\title{
Televisión y fútbol en la Argentina: del juego al género dramático
}

\author{
Pablo ALABARCES
}

\section{INTRODUCCIÓN}

En un relato de Jorge Luis Borges y Adolfo Bioy Casares (con el seudónimo de Bustos Domecq), publicado en 1963 y titulado "Esse est percipi", un dirigente deportivo le confiesa al narrador:

El último partido de fútbol se jugó en esta capital el día 24 de junio del 37. Desde aquel preciso momento, el fútbol, al igual que la vasta gama de los deportes, es un género dramático, a cargo de un solo hombre en una cabina o de actores con camiseta ante el cameraman (Borges y Bioy Casares, 1996: 133).

En la imaginación de los autores se desata una posibilidad que el mapa de medios masivos en la Argentina de los primeros sesenta, en principio, no autoriza: la realidad, en el cuento, se construye massmediáticamente, no tiene existencia fuera de un trazo discursivo. Un género dramático: un relato, radial, gráfico o televisivo. Y si es una imaginación no autorizada, se debe a que es pretelevisiva: en esos años, la televisión argentina recién inicia su despegue hacia la masificación, no ocupa -de ninguna manera- el espacio inconmensurable con el que hoy dibuja la vida cotidiana. Pero Borges y Bioy Casares anuncian una posibilidad semiótica y también tecnológica: digitalización de la imagen mediante, el partido virtual puede tener lugar hoy, ser puro simulacro. 
Posibilidad cultural: en la futbolización de la sociedad contemporánea (Alabarces, 1997), y en la deportivización de la industria del espectáculo, un tiempo donde el fútbol sea puro discurso sin referente, único género massmediático masculino, no parece sólo una utopía borgeana. Como intentaremos analizar, en el creciente influjo de las lógicas espectaculares de los medios sobre el deporte puede leerse una tensión no resuelta. Que de solucionarse en favor del polo massmediático significaría decididamente el escenario que, risueñamente, proponen Borges y Bioy.

\section{2.}

La televisión argentina comienza sus transmisiones regulares el 17 de octubre de 1951, con la puesta en el aire de un acto político masivo del entonces gobernante peronismo, desde la Plaza de Mayo de Buenos Aires. La siguiente transmisión directa fuera de estudios ocurre unos días más tarde, con otro espectáculo masivo, aunque ya no político: San Lorenzo-River, desde el estadio del primero, el 3 de noviembre de ese año. Allí comienza una larga historia, que no vamos a narrar aquí; pero sí quiero señalar esta coincidencia, para

1. Véase Varela en este mismo volumen. nada casual, de dos fundaciones: la de la televisión y la del fútbol por televisión en la Argentina ${ }^{1}$.

Nacimiento simultáneo de un medio y su espectáculo predilecto, ese momento fundacional inaugura una historia que coloca al fútbol como atractor de una serie tecnológicacultural: en 1978, el equipamiento que la Argentina debe adquirir para transmitir el Mundial de Fútbol le permite inaugurar al año siguiente las transmisiones regulares de color; en 1991, la emisión de partidos de fútbol permite el comienzo de la explotación de los sistemas de codificación de señales por cable, a las que el espectador accede mediante el pago de una prima especial; simultáneamente, la comercialización de la transmisión de partidos de fútbol hacia el interior de la Argentina, exclusivamente por sistemas de cable, motiva una explosión de los hogares abastecidos por el sistema, que coloca a la Argentina en el primer lugar sudamericano (sólo relegado por Estados Unidos en el mundo) en cantidad de abonados en relación con la población (cerca de cinco millones de abonados, aproximadamente trece millones de espectadores, $40 \%$ de la población argentina).

La presencia del deporte en general en la pantalla ha venido creciendo exponencialmente en los últimos años. En el caso de la televisión por aire, hemos pasado de tres progra- 
mas regulares semanales en las emisoras porteñas ${ }^{2}$ (uno de fútbol, uno de boxeo, uno de automovilismo), de seis horas semanales en conjunto, con ciclos que desaparecian de escena por fracasos en el rating, a una superpoblación de 26 horas semanales deportivas, 13 de ellas de fútbol, sobre un total aproximado de 455 horas semanales entre las cinco emisoras de Buenos Aires. Y esto sin contar con las emisiones especiales dedicadas a eventos extraordinarios, tales como los partidos de la selección nacional de fútbol, las copas internacionales latinoamericanas de clubes, las finales de la NBA o los Juegos Olímpicos y campeonatos mundiales, períodos durante los cuales -especialmente en los últimos- es casi imposible escapar al deporte televisado. Asimismo, la regularidad con que uno o más equipos argentinos participan de las copas latinoamericanas (Libertadores, Supercopa) puede elevar la cifra de horas semanales dedicadas al deporte a 32, 19 de ellas exclusivamente futbolísticas ${ }^{3}$.

La ya señalada presencia y extensión de la transmisión por cable expande este fenómeno. Hay tres señales permanentes presentes en casi todos los operadores, dos de ellas internacionales (norteamericanas) y una argentina: ESPN y Fox Sports América, las primeras, TyC Sports, la segunda. Esta última es el canal de deportes de la empresa Torneos y Competencias, virtual monopolio (o, al menos, principal operador) de las emisiones deportivas argentinas, en este caso asociado con el Grupo Clarín, el mayor emporio multimedios del país. La monopolización de la transmisión de los partidos de fútbol de los torneos de la Asociación del Fútbol Argentino (AFA) que detenta Torneos y Competencias, y que distribuye principalmente a través de su señal de cable, virtualmente obliga a los operadores de cable a contratar la señal de TyC Sports (recordemos que el atractivo del fútbol es una de las principales razones para la extensión del cable en la Argentina), por lo que el $70 \%$ de los abonados recibe esa señal.

Junto a estos tres canales principales (ESPN y TyC cuentan con notoria ventaja en las preferencias), cada operador de cable "inventa" su propio canal: Cablevisión deportes, Multicanal deportes, etc., los que integran su programación con la contratación de eventos particulares (los que escapan al control de TyC) y programas deportivos monográficos -dedicados a deportes particulares-o espacios pagados, muchos de ellos partidarios o personales. En el cable abundan las producciones dedicadas exclusivamente a cubrir las campañas de clubes particulares, a discutir sus avatares, a producir formas televisivas de terapia de grupo; los espacios no son sostenidos económicamente por las instituciones, sino por
2. El $90 \%$ de la producción audiovisual argentina se concentra en Buenos Aires y se irradia desde alli (por repetidoras, por satélite o por cable) hacia el resto del país.

3. Y seis horas corresponden a "noticieros deportivos", en los que la presencia del fútbol es abrumadora. 
grupos de hinchas que se autotitulan periodistas deportivos y se financian con publicidades diversas (aunque se sospeche de la vinculación de los anunciantes con la divisa). Ésta es una paradoja productiva del cable argentino: a pesar de ser una tecnología que designa la etapa globalizadora del capitalismo, al mismo tiempo permite una entrada fuerte de las lógicas localizadoras, las que señalan la persistencia de identidades segmentadas (o tribalizadas, en términos de Maffesoli, 1990).

Lo cierto es que esa extensión del cable y de su programación deportiva nos habla de un total de 144 horas diarias -1.000 semanales- disponibles para el aficionado deportivo con acceso al cable, muchas de ellas dedicadas al fútbol. Pero además, en lo que respecta específicamente a éste, el mapa designa una extraordinaria masa monetaria puesta en juego en torno suyo. La exclusividad de los derechos de transmisión para Torneos y Competencias implica un contrato de monopolio de la imagen hasta el año 2010, a cambio de US\$10 millones anuales para la AFA, y sumas siderales (para el mercado argentino) para los clubes. Torneos y Competencias transmite un partido los viernes, por el que abona US\$230 mil (US\$9 millones anuales), que se reparten en proporción de 65-35 según el beneficiario sea un club grande (Boca, River, Racing, San Lorenzo, Independiente o Vélez) o "chico"; otro partido los sábados, a cambio de US\$160 mil (US\$6 millones anuales), entre un club grande de Buenos Aires y un equipo del interior de la Argentina, repartiéndose la suma en la misma proporción; otro los domingos, generalmente entre dos grandes de Buenos Aires, que se reparten US\$300 mil (unos US\$13 millones por año). Finalmente, Torneos y Competencias inventó otro partido los lunes, entre dos equipos chicos, que significa un reparto de US\$300 mil anuales. Esto le permite a los clubes obtener ingentes adelantos, al comenzar cada temporada, por concepto de derechos televisivos. Los clubes recaudan aproximadamente US\$30 millones anuales por derechos, junto a otros US\$11 millones por concepto de publicidad estática en los estadios $\mathrm{y}$ auspicio en las camisetas, mientras que los canales facturan unos US\$35 millones anuales por publicidad. Torneos y Competencias obtiene, sólo por concepto de pagos de los abonados al cable, unos US\$65 millones. Las distintas estimaciones fijan la facturación bruta de la empresa en cerca de US\$170 millones anuales.

El fútbol funciona, entonces, como principio de causalidad en relación con la industria televisiva. Entonces, una de las preguntas a desarrollar es hasta qué punto la industria 
opera como principio de causalidad de cambios que se producen dentro de la serie estrictamente deportiva, si de esa manera podemos denominar los aspectos relacionados con la lógica del juego antes que con los espectaculares.

\section{3.}

El aumento en la cantidad de horas emitidas, y especialmente en la cantidad de partidos transmitidos televisivamente, la mayoría de ellos en directo y a través de señales codificadas, dispara nuestra reflexión en varias direcciones. La primera: los costos de un partido codificado son mucho más elevados en el interior de la Argentina que en Buenos Aires, debido a una ecuación monetaria muy sencilla, según la cual si el espectador porteño decide no abonar la tarifa, puede asistir al estadio. Hoy, la tarifa mensual del servicio codificado en Buenos Aires es similar al precio de una entrada popular. Por el contrario, en el interior la tarifa es hasta cuatro veces más alta: los habitantes de ciudades distantes dos mil kilómetros de la capital argentina no tiene otra forma de espectación que la televisiva.

Pero también: a pesar del incremento en la cantidad de partidos en pantalla, y la relativa reducción de costos, no hay indicios de un decrecimiento en la cantidad de espectadores en los estadios. La clásica y apocalíptica relación inversamente proporcional entre cantidad de partidos televisados y asistentes a las canchas nunca ha sido demostrada. En las razones de los temporarios decrecimientos de asistencia han incidido otros factores: inseguridad, violencia, etapas económicas recesivas que agudizan la caída del poder adquisitivo de las clases medias y populares. Pero no la televisión.

La televisión, a pesar de estrategias narrativas -que analizaremos más adelante- que tienden a perfeccionar las formas de ver, a suplantar las miradas de los aficionados de manera absoluta, y a pesar de la mayor comodidad -y hasta un relativo abaratamiento- no ha conseguido producir un último relevo. Las formas de ver implican también formas de espectación y la asistencia al estadio, aun con las diferentes prácticas que distintos asistentes y distintos espacios de concurrencia designan, significa una forma de actividad irreemplazable. En la cultura futbolística argentina -no sólo en ella- continúa vigente, de manera fuerte, un principio que rige toda práctica: la asistencia al estadio -el ejercicio de sus rituales- es una forma fuerte de intervención, a tal punto que, de manera mágica, el hincha supone que su presencia 
puede decidir el resultado. En el canto, en el aliento, en el reproche, en el insulto o en la forma pragmática de la violencia. La asistencia al estadio no significa un número en el detalle de la recaudación por boletería: designa la persistencia de una intervención mítica.

4.

Pero esa intervención aparece, en los últimos tiempos, también intersectada por la lógica espectacular televisiva. Cantos y banderas, soportes tradicionales del discurso de las hinchadas, adquieren nuevas características. Si las banderas dialogaban con el propio colectivo y con el Otro presente, el oponente circunstancial, o el Otro ausente, el rival clásico o el enemigo eterno, las banderas también entablan diálogos que se saben soportados por el lenguaje televisivo. Una bandera no es solamente el territorio emblemático de una pasión, el trofeo, la insignia guerrera; puede ser también el soporte de un mensaje con destinatarios massmediatizados -las hinchadas rivales que se adivinan tras la pantalla- o estrictamente massmediáticos: los propios medios masivos que intervienen en la conversación futbolística. Las banderas (y en muchos casos los cánticos refuerzan estas prácticas) reprochan a un canal de televisión un pretendido favoritismo, a un relator su partidismo, a un comentarista su sujeción a las lógicas de maximización de la ganancia del medio para el que trabaja. La hostilidad puede -nuevamente- asumir formas más pragmáticas: la agresión. Los objetos del deseo de los hinchas ya no son solamente los árbitros y la policia: a veces son los periodistas.

Si este tipo de intervención designa una colocación del espectador hostil al espectáculo televisivo, hay otras que apuntan en la dirección inversa. La aparición de banderas gigantes es una de ellas: a semejanza de ciertas hinchadas europeas, las hinchadas argentinas han comenzado desde hace unos años a desplegar gigantescas banderas que ocupan una cabecera del estadio, testimoniando su adhesión, muchas veces sólo con los colores partidarios. Exceso demostrativo, petulancia competitiva ("la nuestra es más grande"), pero también adecuado manejo de un lenguaje televisivo: la bandera gigante reclama el plano general, impone al director de cámaras una imagen. Leyendo desde otro lugar: la bandera gigante parece la adecuación de la hinchada a un lenguaje ajeno, que domina la lógica de la conversación e impone sus reglas estéticas: las banderas son televisivas, además de televisadas. 
De la misma manera, uno de los rasgos más comunes de la "carnavalización" de los comportamientos de las hinchadas, el disfraz, la pintura del rostro, la vestimenta insólita, es capturada en y por el lenguaje del espectáculo. La carnavalización personal ya no señala únicamente el territorio de la fiesta, de la violación de la regla y la inversión de la jerarquia: también designa, indirectamente, el vestuario del espectáculo. Adultos y niños, hombres y mujeres, desfilan, antes de entrar al estadio, delante de las cámaras; una vez registrada su participación massmediática, el objetivo está cumplido. Y el carnaval, neutralizado en la cinta de video.

\section{5.}

La tecnología del relato televisivo pretende una neutralidad basada en su asepsia y en la multiperspectividad: cámaras desde todos los ángulos, desde planos aéreos hasta detalles. No es una mirada más: son todas las miradas posibles. Nadie puede ver todo lo que la televisión ve. La tecnología se dice como enunciador: es la posibilidad de constituir el panóptico, de desplegar una multiplicidad de miradas tal que erija al relato televisivo en un punto de vista unitario en su diversidad. Hasta violar la regla del contracampo: si el ojo que soporta básicamente el relato es el lateral, la mirada puede girar 180 grados para leer el otro lateral (violación marcada de la regla, con la leyenda "ángulo invertido"). La disposición de cámaras sugiere el reemplazo absoluto del espectador: todas las posiciones posibles, todas las variadas alternativas de las que el asistente al estadio dispone son relevadas por la generación de imágenes televisivas.

El uso del plano detalle trabaja, también, en una lógica melodramática. El ojo del primer plano busca obsesivamente el desborde, el exceso, el cuerpo significante que el deporte pone en escena de manera desmesurada. El género se contamina con el melodrama, pero no como pauta massmediática, no como imposición proveniente del interior del medio: es la lógica futbolística misma la que obliga a la contaminación, es el cuerpo excesivo del juego el que exige este tratamiento. El deporte, y el fútbol con particular belleza, es despliegue de estrategias corporales, es escenario de argumentaciones preletradas. Es pasión, pasión abrasadora, derroche inútil y excesivo de energías improductivas, apenas productoras de sentido.

Pero el detalle también es policíaco. El Hermano Mayor vigila atentamente: nada escapa a su percepción, nada pue- 
de huir de su mirada controladora. La cámara es una gran productora de pruebas, de confianzas irrefutables: es la garantía, porque es a la vez imaginaria, analógica, sobreimpresa, con la perfección digitalizadora del telebeam, el procesamiento informático de las imágenes polémicas. El relato se articula, entonces, como un juicio. Terminado el espectáculo, los jueces se instalan frente a una pantalla que reproduce la jugada dudosa, amplificada y multiplicada; la cámara nos revela el instante fatal; la imagen se congela en el momento preciso (¿cuál es el momento preciso? ¿el primer fotograma o el segundo?) en que el jugador golpea a su adversario dentro del área para merecer la condena inapelable. No hay duda, fue penal. La imagen no miente, es el análogo perfecto: la computadora no miente, es la cientificidad.

La imagen no miente: la imagen habla, derrocha sentidos sin relevos innecesarios. Aquí está la mayor innovación del relato futbolístico televisivo en la Argentina: una mayor penetración del lenguaje cinematográfico -también técnicamente: Torneos y Competencias registra un relato íntegro en soporte filmico, para su edición posterior- tiende a señalar, indirectamente, que en la televisión y en el fútbol se habla -lingüisticamente- mucho, sin ser necesario. La edición de un telefilme con el desarrollo integro de un torneo, en 1995, sin utilizar narrador en off, sin una sola palabra fuera del sonido de ambiente, parece demostrarlo.

6.

La dependencia que analizábamos más arriba entre fútbol y televisión, la imbricación entre ingresos por derechos televisivos y economía de los clubes, tiene implicancias severas. La transmisión televisiva, como explicamos, selecciona y distingue entre equipos poderosos y débiles. La derivación obvia es simple: los éxitos deportivos de los clubes grandes son festejados por la industria cultural, que ve tras ellos la maximización de la ganancia -del rating, del merchandising, de la venta de ejemplares de periódicos y revistas especializadas-. La irrupción de un equipo "chico", por el contrario, se adivina amenazante para esta lógica. Pero además, al ser la exhibición televisiva el principal soporte económico, la organización del cronograma de partidos se sujeta a sus reglas. Los fixtures ya no se sortean en la Argentina: se diseñan atendiendo, estrictamente, a las posibilidades televisivas de cada domingo (y viernes, y sábado, y lunes...). 
Los rastros de esta tendencia se leen entre líneas, pero se configuran como un crescendo paranoico. Todo resultado insólito, toda racha adversa prolongada, todo fallo arbitral desmesurado se entiende, en el imaginario del hincha, como la acción tenebrosa de los monopolios multimedios. Hay indicios que refuerzan la hipótesis conspirativa: las empresas televisivas incursionan en la compra y venta de jugadores y, en tanto propietarias de un pase, se les supone interesadas en su exhibición, independientemente de su desempeño. En 1994, Torneos y Competencias adquirió el pase del jugador Cedrés a Argentinos Juniors una fecha antes del final del campeonato, para cederlo a River Plate. Nadie desconocía que en el último partido ambos clubes se enfrentaban, que la empresa lo transmitía, que River disputaba el campeonato, que la empresa ya había contratado los festejos del título, que, en consecuencia, el partido tenía un solo resultado posible, y que Cedrés no podía hacer un gol. Como nadie lo desconocía, nadie desobedeció.

La expansión de la industria televisiva en el fútbol instala un imaginario conspirativo. En el clima social argentino, donde la corrupción de las esferas políticas es un punto central de la agenda, la transferencia es muy sencilla. La sospecha de corrupción generalizada alcanza incluso a los jugadores, auspiciados de manera personal por empresas de gaseosas, o contratados por Torneos y Competencias, o por el Multimedios América, como actores de sus ciclos (como comentaristas, figurines, modelos). Cuando un jugador, al festejar un gol, levanta su camiseta, no lo hace para ofrendar sus colores a su tribuna; lo hace para señalar la imagen de Pepsi Cola que lleva junto a su corazón. La audiencia, multiplicada por miles, asiste a un nuevo recurso de publicidad encubierta, disfrazada de carnaval.

La industrialización del espectáculo futbolístico argentino, antes que a una profesionalización de su tradicionalmente subdesarrollado acontecer, parece tender a su corrupción. Y a la hipertrofia de los juegos paranoicos de sus hinchadas. En 1995, San Lorenzo salió campeón con el apoyo del animador televisivo Marcelo Tinelli, del grupo multimedios Telefé, de la Editorial Atlántida, del embajador James Cheek y la Embajada norteamericana, de grupos pentecostales como los "Atletas de Cristo" y de la Iglesia católica que auspicia una peregrinación a la ciudad de Luján (tradicional destino religioso) organizada por el nombrado Tinelli. Sin embargo, la hinchada de San Lorenzo reclama su victoria contra la AFA, el presidente de la misma, Julio Grondona, el relator televisivo Marcelo Araujo, el Canal 13, el poderoso diario Clarín, el 
empresario Carlos Ávila y Torneos y Competencias. Faltó, únicamente, la KGB. En los juegos de complots, nadie quiere permanecer junto al poderoso. A nadie se le ocurre que, entre otras cosas, el campeonato se debió a los goles oportunos del brasileño Silas.

\section{7.}

La relación entre fútbol y televisión puede leerse, de manera intensa, en esa tensión entablada entre dos lógicas en principio irreductibles: la lógica del juego, procedente de la marca lúdica que por lo menos en inicio impregna todo deporte, y la lógica de la maximización de la ganancia, propia de la mercantilización y la industrialización, irreductible a todo argumento que no contemple costos y beneficios, inversiones y saldos.

El fútbol es importante en nuestra cultura, entre otras razones, porque puede ser el reducto de lo imprevisible. E1 lugar donde el favorito de los medios, omnipotentes, fracase ante el eterno derrotado. Pero además, porque provee infinitos relatos: partido tras partido, desde el comienzo hasta el final la incertidumbre se mantiene, el bueno puede vencer, pero también ser vencido por las fuerzas del mal. La televisión intenta desplazar este desorden: a la caoticidad del juego le enfrenta la rigidez de la industria; a la imprevisibilidad del resultado le imprime la supresión del azar y la manipulación de la agenda de partidos; a la vaguedad, a la aleatoriedad de la jugada, a la transgresión y a la picardía le impone la mirada policíaca que restablezca el orden. A la lógica del juego, lógica de excesos improductivos o del sentido en exceso, lógica del deseo y la fantasía, la industria televisiva le contrapone la lógica del capitalismo, del orden, del control, de la ganancia.

Le contrapone, le imprime, le superpone, le disputa. Todos los términos que describen la tensión insisten en acciones, describen conflictos antes que estados. No pueden, porque no se puede, señalar un desequilibrio. La relación entre fútbol e industria cultural parece definirse sólo en esa tensión perpetua. Ni la tentación populista que denomine la última victoria de las audiencias ni la impugnación apocalíptica que hable del poderío infinito de un emporio multimedios. Es decir: por ahora, un empate. 
Bibliografía

Alabarces, Pablo 1997

“¿De la heteronomía a la continuidad? Las culturas populares en el espectáculo futbolístico". Punto de Vista, XX, 56, Buenos Aires.

Alabarces, P. y M.G. Rodríguez 1996

Cuestión de pelotas. Fútbol, deporte, sociedad, cultura. Buenos Aires: Atuel.

Bechelloni, Giovanni 1995

Televisione come cultura. I media italiani tra identitá e mercato. Napoli: Ligouri.

Borges, J.L. y A. Bioy Casares 1996

Crónicas de Bustos Domecq. Buenos Aires: Losada.

Castañón Rodríguez, Jesús 1993

El lenguaje periodístico del fútbol. Valladolid: Universidad de Valladolid.

De Biase, Pablo 1997

"Pelota, pantalla y nuevos consumos culturales", en Alabarces, P., Fryenberg, J. y Di Giano, R. (eds.). Deporte y ciencias sociales. Buenos Aires: IIGG-CBC (UBA).

Maffesoli, M.

1990

El tiempo de las tribus. Barcelona: Icaria.

Rader, Benjamin 1984

In its Own Image. How Television has Transformed Sports. New York: The Free Press.

Simonelli, Giorgio y Alessia Ferrarotti 1995

I media nel pallone. Stampa, televisione, sport. Milano: Guerini. 
Varela, Mirta

1996

1997

Wenner, Lawrence (editor)

1989
"Del televisor a la televisión: la incorporación de la TV en la Argentina”. Causas y Azares 4. Buenos Aires, invierno.

"Fútbol y espacio público en los comienzos de la televisión argentina", en este mismo volumen.

Media, Sports \& Society. Newbury Park: Sage. 